\section{G255(P) WHERE THERE IS NO SPECIALIST - ADVOCATING FOR CHILDREN WITH NEPHROTIC SYNDROME IN RURAL BANGLADESH}

${ }^{1} \mathrm{R}$ Rhodes, ${ }^{2} \mathrm{M}$ Christian, ${ }^{3} \mathrm{H}$ Imam, ${ }^{3} \mathrm{~S}$ Sarker, ${ }^{3,4} \mathrm{~A}$ Cowper, ${ }^{3} \mathrm{LT}$ Day. ${ }^{1}$ General Medicine, Derby Hospitals Foundation Trust, Derby, UK; ${ }^{2}$ Paediatric Nephrology, Nottingham Children's Hospital, Nottingham, UK; 'PPaediatric Department, LAMB Hospital, Parbatipur, Bangladesh; ${ }^{4}$ Paediatric Department, Barts Health NHS Trust, London, UK

\subsection{6/archdischild-2015-308599.248}

Background Although global child health focuses mainly on child survival priorities, addressed through Integrated Management of Childhood Illness, some common chronic diseases emerge. Nephrotic Syndrome (NS) in children of the Indian subcontinent is six times more prevalent than in white children. Most children have steroid-sensitive disease, presumed to be minimal change disease. In rural areas of low income countries, the early stages of NS are often not recognised by carers and presentation to appropriate medical services occurs late, when serious complications (ascites, thrombosis, infection, hypertension) are already present. Furthermore, concomitant presentation with malnutrition makes clinical assessment more difficult.

This project aimed to describe the demographics and complications of children needing admission at a developing paediatric nephrotic service in rural Bangladesh.

Method A retrospective review of medical records of children admitted with NS between January 2008 and April 2014 was undertaken.

Results As the quality of outpatient service improved with inservice training, structured proformas and guideline-based management, increasing numbers of patients presented. Most were successfully managed as outpatients but there were 79 admissions in 67 children $(0.5 \%$ of all paediatric admissions). More children presented in the cool season in contrast to the usual increase in paediatric admissions during rainy season. There was an expected 2:1 male:female ratio but, less typically, a bimodal age distribution, peaking at 3 and 9 years. Median (IQ range) duration of inpatient admissions was 8 (5-12) days. 8 children (10\%) received treatment for sepsis. 22 admissions (28\%) were for first presentations, 27 (34\%) were for subsequent relapses and 27 (34\%) had received treatment elsewhere for an unknown number of previous relapses. 3 cases lacked record of this detail. Telemedicine advice from a UK specialist was taken for complex cases. There were 4 deaths.

Conclusion In a rapidly changing world, common chronic diseases in the low income setting are emerging as important causes of morbidity and mortality. Establishing a quality, resourceappropriate service for children with NS is important to build trust and relationships which promote good follow-up and early diagnosis of relapse.

\section{G256(P) UNDERSTANDING PARENTS' AND PROFESSIONALS' KNOWLEDGE AND AWARENESS OF AUTISM IN NEPAL}

${ }^{1} \mathrm{~A}$ Alexander, 'L Pellicano, ${ }^{2} \mathrm{E}$ Medeiros, ${ }^{3} \mathrm{KM}$ Tumbahangphe, ${ }^{4} \mathrm{~F}$ Gibbons, ${ }^{2} \mathrm{M}$ Wickenden, ${ }^{5} \mathrm{M}$ Shrestha, ${ }^{2} \mathrm{~A}$ Costello, ${ }^{2} \mathrm{M}$ Heys, ${ }^{3} \mathrm{DS}$ Manandhar. ${ }^{1}$ Centre for Research in Autism and Education, Institute of Education, University College London, London, UK; ${ }^{2}$ Institute of Global Health, University College London, London, UK; ${ }^{3}$ Mother and Infant Research Activities (MIRA), Kathmandu, Nepal; ${ }^{4}$ Institute of Psychiatry, Kings College London, London, UK; ${ }^{5}$ Autism Care Nepal (ACN), Kathmandu, Nepal

10.1136/archdischild-2015-308599.249

Background Autism spectrum disorder (ASD) is a global phenomenon. While in Western countries such as the US and UK, prevalence estimates of ASD are around 1\%, much less is known about its prevalence in other settings. Cross-cultural differences (e.g., in eye gaze processing) have caused some researchers to call for the need to determine culturally specific understandings of ASD, especially in developing and underserved populations like Nepal.

Aims To examine parents and professionals' understanding of typical and atypical development in both rural (Makwanpur District) and urban (Kathmandu Valley) Nepal, focusing specifically on ASD.

Methods In collaboration with our community partners, Autism Care Nepal and Mother and Infant Activities Nepal, we conducted 9 focus groups with health workers, junior and senior paediatricians, primary school teachers and parents of autistic and non-autistic children and 9 semi-structured interviews with early childhood development (ECD) teachers, faith healers, paediatricians and other people working in the disability sector in Makwanpur. The focus group and interview schedules included questions about typical development and vignettes of typically and atypically developing children.

Results Overall, those parents and professionals who were not directly involved with atypically developing children had very little awareness of autism. Participants, particularly parents of nonautistic children, used terms such as "doggedly child", "lonely child", "introvert, "egoistic", "dumb", or "mental patient" to describe vignettes of children with autism. Most participants felt that environmental factors (e.g., parenting style, home or school environment) were key causes of atypical child development. Health and education professionals reported they had received limited training in identification and in particular management of children with atypical development. Many participants called for wider awareness of autism in the community through special schools or media awareness campaigns.

Conclusions This is the first study to examine parents and professionals' understanding of typical and atypical child behaviour and development in rural and urban Nepal. These findings clearly show the lack of awareness of developmental disorders, such as autism, from both parents and professionals alike. These results have important implications for future work aiming to increase awareness and enhance support available for autistic children and families in Nepal.

\section{G257(P) AN OVERSEAS DIPLOMA IN CHILD HEALTH (DCH) CLINICAL TRAINING COURSE AND ASSESSMENT PROGRAMME-LESSONS LEARNED}

${ }^{1}$ A Mathew, ${ }^{2} \mathrm{P}$ Venugopalan, ${ }^{3} \mathrm{D}$ Crane. ${ }^{1}$ Paediatrics, Western Sussex Hospitals NHS Trust, Worthing, UK; ${ }^{2}$ Paediatrics, Royal Alexandra Children's Hospital, Brighton, UK; ${ }^{3}$ Examinations, Royal College of Paediatrics and Child Health, London, UK

\subsection{6/archdischild-2015-308599.250}

Introduction and aim Undergraduate and postgraduate education and training differ across nations in the emphasis placed on the knowledge, skills and attitudes within the training curriculum. In the DCH (UK) clinical examination, candidates are assessed in all areas of the doctor-patient interaction; skills in communication, proficiency in all areas necessary for a comprehensive assessment and management of the patient have to be demonstrated. This abstract describes the experience of doctors who participated in the first overseas RCPCH DCH (UK) clinical training course and pilot examination.

Methods 5 UK faculty members supported by 5 Indian faculty members delivered a 2-day DCH (UK) training course and pilot 


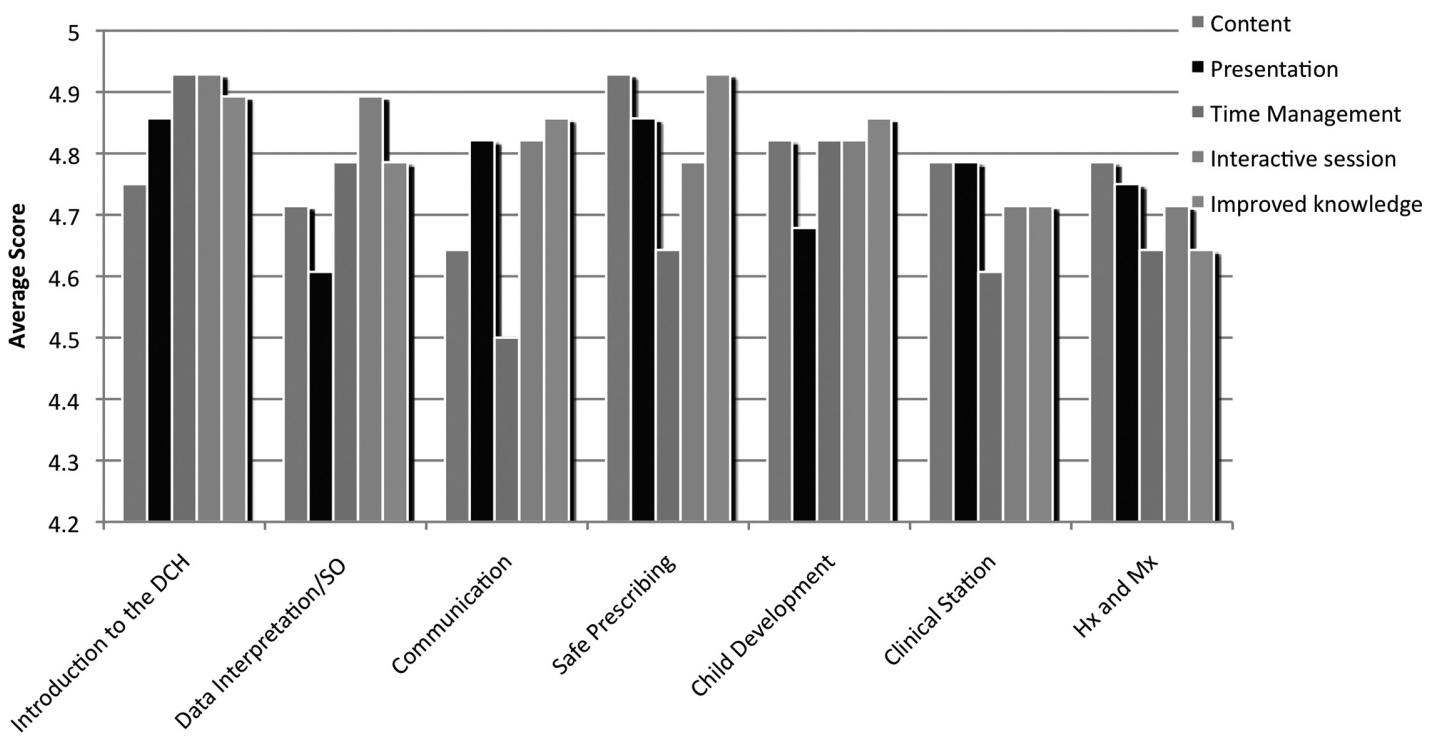

Abstract G257(P) Figure 1 DCH(UK) training course feedback Kolkata 2014

assessment in India. 32 candidates attended, the target number set by the RCPCH. On day-1, training was provided around the stations in the examination circuit and feedback sought utilising a questionnaire survey represented on a scale of $1-5,1$ indicating very poor, 5 indicating excellent. Averaged scores are displayed graphically (Figure1). On day-2, a pilot examination was held, and feedback sought through a questionnaire survey utilising a 7-point Likert scale (Figure 2). Free text comments were invited on both days (Table 1).

Results 29 of the 32 candidates provided feedback on day 1, 31 of the 32 on Day 2. Candidates expressed deep appreciation of this experience of teaching and training. They emphasised a desire to have further training, in all aspects of the course, stressing the importance for more-time and patient contact per session. They appreciated the different emphasis placed in UK postgraduate training, where communication, an empathetic approach, and good clinical examination and interpretive skills are the core skills assessed in our examination. The collaborative, supportive and welcoming approach displayed by the faculty of examiners was also widely appreciated.
Conclusion The results obtained from this course provide evidence that such teaching and training is highly valued; with expressions of interest for further training. Pertinent feedback around how to improve future courses will be considered carefully and addressed in order to develop a sustainable overseas programme.

\section{G258(P) A TWELVE MONTH REVIEW OF PAEDIATRIC INTENSIVE CARE IN MYANMAR TO GUIDE SERVICE DEVELOPMENT}

1J Halbert, ${ }^{2} \mathrm{~L}$ Martin, ${ }^{3} \mathrm{~T}$ Zaw, ${ }^{4} \mathrm{RT}$ Vasquez Rivera. ${ }^{1}$ Department of Paediatrics, Lister Hospital, Stevenage, UK; ${ }^{2}$ Royal Free Hospital, London, UK; ${ }^{3}$ Department of Paediatrics, Yangon Children's Hospital, Yangon, Myanmar; ${ }^{4}$ Department of Obstetrics and Gynaecology, Hospital de Figueres, Figueres, Girona, Spain

\subsection{6/archdischild-2015-308599.251}

Aims Reliable healthcare statistics are limited in Myanmar. This study aims to describe the typical patient journey through a Paediatric Intensive Care Unit (PICU) and provide vital information to guide future development.

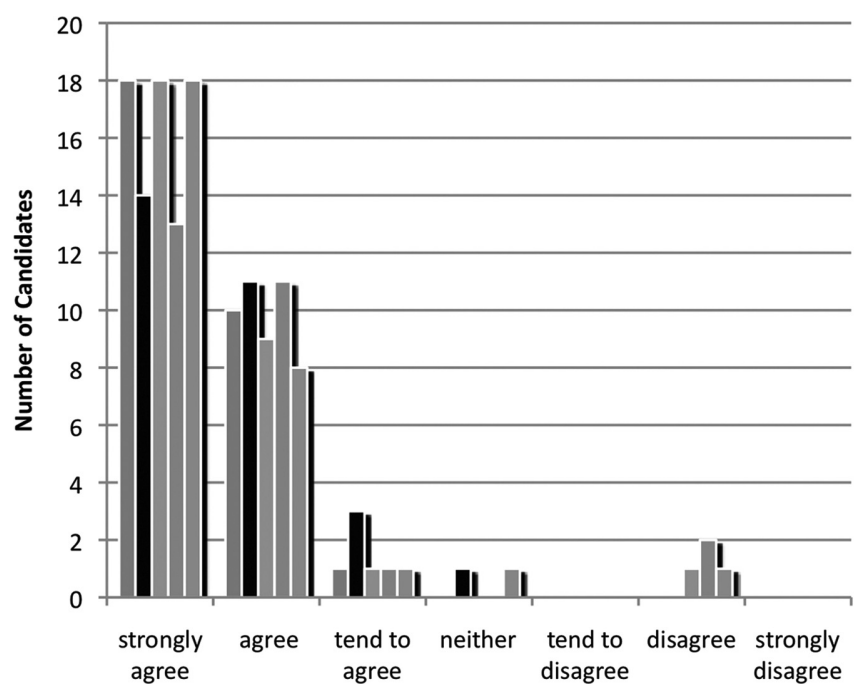

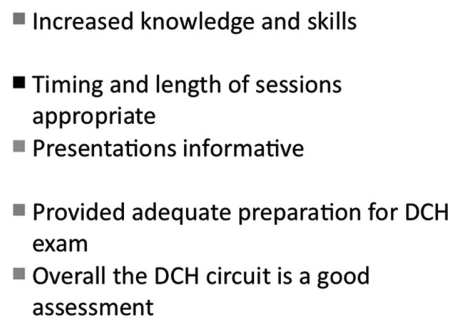

assessment

Abstract G257(P) Figure 2 DCH(UK) pilot examination feedback Kolkata 2014 